Fixed Point Theory, 22(2021), No. 2, 465-480

DOI: $10.24193 /$ fpt-ro.2021.2.31

http://www.math.ubbcluj.ro/ nodeacj/sfptcj.html

\title{
NOTES ON KRASNOSELSKII-TYPE FIXED-POINT THEOREMS AND THEIR APPLICATION TO FRACTIONAL HYBRID DIFFERENTIAL PROBLEMS
}

\author{
H. AKHADKULOV*, T.Y. YING*, A.B. SAABAN*, M.S. NOORANI** AND H. IBRAHIM* \\ * School of Quantitative Sciences, University Utara Malaysia, \\ CAS 06010, UUM Sintok, Kedah Darul Aman, Malaysia \\ E-mail: habibulla@uum.edu.my \\ ** School of Mathematical Sciences, Faculty of Science and Technology, \\ University Kebangsaan Malaysia, 43600 UKM Bangi, Selangor Darul Ehsan, Malaysia
}

\begin{abstract}
In this paper we prove a new version of Kransoselskii's fixed-point theorem under a $(\psi, \theta, \varphi)$-weak contraction condition. The theoretical result is applied to prove the existence of a solution of the following fractional hybrid differential equation involving the Riemann-Liouville differential and integral operators orders of $0<\alpha<1$ and $\beta>0$ :
\end{abstract}

$$
\left\{\begin{array}{l}
D^{\alpha}[x(t)-f(t, x(t))]=g\left(t, x(t), I^{\beta}(x(t))\right), \text { a.e. } t \in J, \beta>0, \\
x\left(t_{0}\right)=x_{0},
\end{array}\right.
$$

where $D^{\alpha}$ is the Riemann-Liouville fractional derivative order of $\alpha, I^{\beta}$ is Riemann-Liouville fractional integral operator order of $\beta>0, J=\left[t_{0}, t_{0}+a\right]$, for some fixed $t_{0} \in \mathbb{R}, a>0$ and the functions $f: J \times \mathbb{R} \rightarrow \mathbb{R}$ and $g: J \times \mathbb{R} \times \mathbb{R} \rightarrow \mathbb{R}$ satisfy certain conditions. An example is also furnished to illustrate the hypotheses and the abstract result of this paper.

Key Words and Phrases: Fixed-point theorem, Riemann-Liouville fractional derivative, hybrid initial value problem.

2020 Mathematics Subject Classification: 26A33, 34A08, 34A12, 47H07, 47H10.

Acknowledgement. The authors are grateful to the editor-in-chief and referees for their accurate reading and useful suggestions. We would like to thank the Ministry of Education of Malaysia for providing us with the Fundamental Research Grant Scheme (FRGS/1/2018/STG06/UUM/02/13 Code S/O 14192).

\section{REFERENCES}

[1] H. Akhadkulov, S.M. Noorani, A.B. Saaban, F.M. Alipiah, H. Alsamir, Notes on multidimensional fixed-point theorems, Demonstr. Math., 50(2017), 360-374.

[2] H. Akhadkulov, A.B. Saaban, S. Akhatkulov, F. Alsharari, F.M. Alipiah, Applications of multidimensional fixed point theorems to a nonlinear integral equation, Int. J. Pure Appl. Math., $\mathbf{1 1 7}(2017)$, no. 4, 621-630.

[3] H. Akhadkulov, A.B. Saaban, M.F. Alipiah, A.F. Jameel, On applications of multidimensional fixed point theorems, Nonlinear Funct. Anal. Appl., 23(2018), no. 3, 585-593.

[4] T.A. Burton, A fixed-point theorem of Krasnoselskii, Appl. Math. Lett., 11(1998), no. 1, 85-88. 
[5] B.C. Dhage, A fixed point theorem in Banach algebras with applications to functional integral equations, Kyungpook Math. J., 44(2004), 145-155.

[6] B.C. Dhage, Hybrid fixed point theory in partially ordered normed linear spaces and applications to fractional integral equations, Differential Equations \& Applications, 5(2013), no. 2, 155-184.

[7] B.C. Dhage, Some variants of two basic hybrid fixed point theorems of Krasnoselskii and Dhage with applications, Nonlinear Stud., 25(2018) no. 3, 559-573.

[8] B.C. Dhage, Dhage iteration method for approximating solutions of IVPs of nonlinear second order hybrid neutral functional differential equations, Indian Journal of Industrial and Applied Mathematics, 10(2019), no. 1, 204-216.

[9] B.C. Dhage, S.B. Dhage, K. Buvaneswari, Existence of mild solutions of nonlinear boundary value problems of coupled hybrid fractional integro-differential equations, Journal of Fractional Calculus and Applications, 10(2019), no. 2, 191-206.

[10] B.C. Dhage, S.B. Dhage, N.S. Jadhav, The Dhage iteration method for nonlinear first order hybrid functional integrodifferential equations with a linear perturbation of the second type, Recent Advances in Fixed Point Theory and Applications, Nova Science Publishers, (2017).

[11] B.C. Dhage, N.S. Jadhav, Basic results in the theory of hybrid differential equations with linear perturbations of second type, Tamkang J. Math., 44(2013), no. 2, 171-186.

[12] B.C. Dhage, V. Lakshmikantham, Basic results on hybrid differential equations, Nonlinear Anal., Real World Appl., 4(2010), 414-424.

[13] S. Heikkilä, V. Lakshmikantham, Monotone Iterative Technique for Nonlinear Discontinues Differential Equations, Marcel Dekker Inc., New York, 1994.

[14] A.A. Kilbas, H.M. Srivastava, J.J. Trujillo, Theory and Applications of Fractional Differential Equations, Elsevier, Amsterdam, 2006.

[15] M. Krasnoselskii, Topological Methods in the Theory of Nonlinear Integral Equations, Macmillan, New York, NY, USA, 1964.

[16] E. Kreyszig, Introductory Functional Analysis with Applications, Wiley, New York, 1978.

[17] H. Lu, S. Sun, D. Yang, H. Teng, Theory of fractional hybrid differential equations with linear perturbations of second type, Bound. Value Probl., 23(2013), 1-16.

[18] I. Podlubny, Fractional Differential Equations, Academic Press, New York, 1999.

[19] F. Shaddad, M.S. Noorani, S.M. Alsulami, H. Akhadkulov, Coupled point results in partially ordered metric spaces without compatibility, Fixed Point Theory and Applications, 2014204 , (2014), https://doi.org/10.1186/1687-1812-2014-204.

[20] D.R. Smart, Fixed Point Theorems, Cambridge University Press, Cambridge, 1980.

Received: June 12, 2019; Accepted: March 27, 2020. 
